\title{
Adhesion, Penetration and Intracellular Replication of Legionella pneumophila: an in vitro Model of Pathogenesis
}

\author{
By LOUISE J. OLDHAM AND FRANK G. RODGERS*† \\ Department of Microbiology and PHLS Laboratory, University Hospital, \\ Queen's Medical Centre, Nottingham NG7 2UH, UK
}

(Received 5 September 1984 ; revised 14 November 1984)

Legionella pneumophila attached to, penetrated and replicated within the three eukaryotic cell lines, MRC-5, HEp-2 and Vero. Multiplication occurred rapidly in these cells for an initial $48 \mathrm{~h}$ after inoculation and declined thereafter. Infected MRC-5 cell monolayers developed lytic-type cytopathic changes, with organisms being readily released. HEp- 2 cells showed a more chronic infection, with slowly developing granular changes in the monolayers, and slow release of intracellular bacteria. In Vero cells, organisms were released rapidly along with a more progressively developing granular cytopathic effect in the monolayers. L. pneumophila was unable to grow in cell-free culture fluids. Uptake and intracellular development was similar for each cell type, and was initiated by 'bacteriopexis', a process in which the organisms bound via receptors and were surrounded by cellular microvilli which eventually fused, leading to bacterial engulfment. Replication of organisms in vacuoles within the cytoplasm of infected cells was confirmed by thorium labelling. These vacuoles were lined with ribosomes and, at the early stages of intracellular development, were found in close proximity to mitochondria, cytoplasmic filaments and banded enclosures. Ruthenium red staining showed that acid mucopolysaccharide capsular material was not present on these organisms during the attachment process or intracellular phase. Organism release was by lysis of the infected cells.

\section{INTRODUCTION}

Legionella pneumophila, the most commonly occurring aetiological agent of legionellosis in man, is a facultative intracellular pathogen. Dividing forms of the organism have been observed in the cytoplasm of alveolar macrophages in post-mortem human lung tissues from cases of Legionnaires' disease (Rodgers et al., 1978; Chandler et al., 1979; Glavin et al., 1979; Rodgers, 1979). The intracellular location of the bacteria has also been reported in laboratory animals including guinea-pigs and rats (Davis et al., 1982; Winn et al., 1982). Intracellular replication of L. pneumophila in vitro has been shown in cultured cell lines (Wong et al., 1980; Daisy et al., 1981), animal derived alveolar and peritoneal macrophages (Kishimoto et al., 1979, 1981) and human monocyte cultures (Horwitz \& Silverstein, 1980). Conversely, it has been shown that organisms were taken up by human polymorphonuclear leucocytes, but failed to replicate (Horwitz \& Silverstein, 1981). Although pili (Rodgers et al., 1980) and numerous other structures (Flesher et al., 1979; Rodgers \& Davey, 1982) have been visualized on the surfaces of $L$. pneumophila, the nature of attachment and penetration of these organisms to eukaryotic cells has remained unclear (Rodgers, 1983). Intracellular survival and subsequent replication probably depend upon a bacterial cytotoxin-induced interruption of the phagolysosomal process (Friedman et al., 1982).

† Present address: Department of Microbiology, Spaulding Life Sciences Building, University of New Hampshire, Durham, NH 03824, USA.

Abbreviations: $\mathrm{PBH}$, poly- $\beta$-hydroxybutyrate; SEM, scanning electron microscopy; TEM, transmission electron microscopy. 
To evaluate the interaction of $L$. pneumophila with cells in culture, the sequence of events from attachment to penetration, intracellular growth and release of organisms in mammalian cells was studied by optical and electron microscopy. The structural findings were correlated with viable counts made simultaneously on cell cultures, together with the ability of legionellae to replicate in cell-free extracellular fluids.

\section{METHODS}

Bacteria and cultication. L. pneumophila serogroup 1, strain Nottingham N7, a clinical isolate from sputum, was passaged once on buffered enriched blood agar containing a low concentration of sodium chloride (LBA; Dennis et al., 1981). Cultures were grown at $36^{\circ} \mathrm{C}$ for $48 \mathrm{~h}$. Organisms were harvested and suspended in Hanks' balanced salt solution without antibiotics (HBSS) to give a concentration of $2 \times 10^{7}$ c.f.u. $\mathrm{ml}^{-1}$.

Cell cultures. Three laboratory cell lines were used: MRC-5, a semi-continuous cell line of human embryonic lung fibroblasts, and the two transformed cell lines, Vero (African Green Monkey) and HEp-2 (human epithelial laryngeal carcinoma). Cells were grown as monolayers in tubes and on glass coverslips at $36^{\circ} \mathrm{C}$ until confluent. After rinsing in HBSS, the MRC-5 and HEp-2 cultures were maintained on antibiotic-free Eagle's minimum essential medium (MEM) and the Vero cells on 199 medium. Both were supplemented with $5 \%(v / v)$ foetal calf serum, $2 \mathrm{~mm}$-glutamine and $0.5 \mathrm{M}-\mathrm{NaHCO}_{3}$. Aliquots of $0.1 \mathrm{ml} \mathrm{L}$. pneumophila suspension were added to the washed cells and incubated at $37^{\circ} \mathrm{C}$ for $2 \mathrm{~h}$ to allow adsorption to occur. The cells were washed free of unattached organisms, reincubated with the appropriate fresh medium and examined daily for the development of cytopathic effects.

Viable counts. Attachment of L. pneumophila to each cell type was determined on LBA from counts made from washed cell monolayers lysed in distilled water after the $2 \mathrm{~h}$ adsorption period by serial dilution of lysate aliquots. Intracellular replication of the organisms in the eukaryotic cells was similarly assessed at $24 \mathrm{~h}$ intervals. To assay release of bacteria from cells into the suspending menstruum, extracellular fluids were harvested daily. Each cell line was then washed three times in HBSS and the fluids and washings from each cell type and time were pooled for viable counts. In addition, aliquots of supplemented cell-free MEM and 199 culture media, previously inoculated with $L$. pneumophila, were assayed daily to evaluate extracellular replication.

Electron microscopy: At daily intervals, infected and uninoculated control monolayers were fixed in situ for $1 \mathrm{~h}$ in $3 \%(\mathrm{v} / \mathrm{v})$ glutaraldehyde in $0 \cdot 1 \mathrm{M}$-cacodylate buffer containing $10 \mathrm{~mm}-\mathrm{MgSO}_{4}, \mathrm{pH} 7 \cdot 2$. For scanning electron microscopy (SEM), samples were dehydrated, critical-point dried and coated with $40 \mathrm{~nm}$ of gold in a Balzers sputter coater. For thin-section transmission electron microscopy (TEM), cells were pre-embedded in molten $2 \%$ $(\mathrm{w} / \mathrm{v})$ agarose, post-fixed in $1 \%(\mathrm{w} / \mathrm{v}) \mathrm{OsO}_{4}$, dehydrated in ethanol and embedded in Epon-Araldite. In addition, infected and control monolayers were treated with ruthenium red to stain for acid polyanions such as mucopolysaccharides (Rodgers, 1979). Further monolayers were washed in $3 \%(\mathrm{v} / \mathrm{v})$ acetic acid after postfixation, and surface labelled with $0.5 \%(\mathrm{w} / \mathrm{v})$ thorium colloid (Polysciences Ltd, Northampton, UK) in $3 \%$ acetic acid for $16 \mathrm{~h}$ at $4{ }^{\circ} \mathrm{C}$. Unattached thorium was removed by washing with acetic acid followed by cacodylate buffer. The monolayers were then embedded for TEM. Ultra-thin sections were obtained on an LKB Ultratome III and stained with uranyl acetate and lead citrate. All samples were examined in a Jeol 100C Temscan electron microscope used at $40 \mathrm{kV}$ in the SEM mode and $100 \mathrm{kV}$ for TEM.

\section{RESULTS}

Viable counts

Attachment of $L$. pneumophila to each of the three cell lines occurred rapidly, but with low efficiency, and by $2 \mathrm{~h}$ of incubation approximately $1 \%$ of the bacteria in the inoculum were bound to the eukaryotic cell receptors. Such organisms could not be removed from the cell monolayers by repeated washings. Although the difference in the final uptake of $L$. pneumophila by each cell type was not large, uptake was greatest for HEp-2 and least for Vero cells (Fig. $1 a$ ). In Vero cells, intracellular replication progressed rapidly for an initial period of $48 \mathrm{~h}$ after inoculation, and slowed thereafter, with a peak at $72 \mathrm{~h}$. This was followed by a decline in the number of intracellular organisms present over the remaining $72 \mathrm{~h}$. The highest titres of intracellular organisms were recorded with these cells. Similar results were obtained for HEp-2 cells, but the slower phase of intracellular multiplication of organisms occurred after only $24 \mathrm{~h}$. The lung fibroblasts showed a peak of intracellular replication of organisms at $48 \mathrm{~h}$ after inoculation and this was followed by a sharp decline in bacterial numbers. This finding was in keeping with the more rapidly lytic infection of these cells leading to the liberation of organisms into the extracellular fluids (Fig. $1 a$ ). 


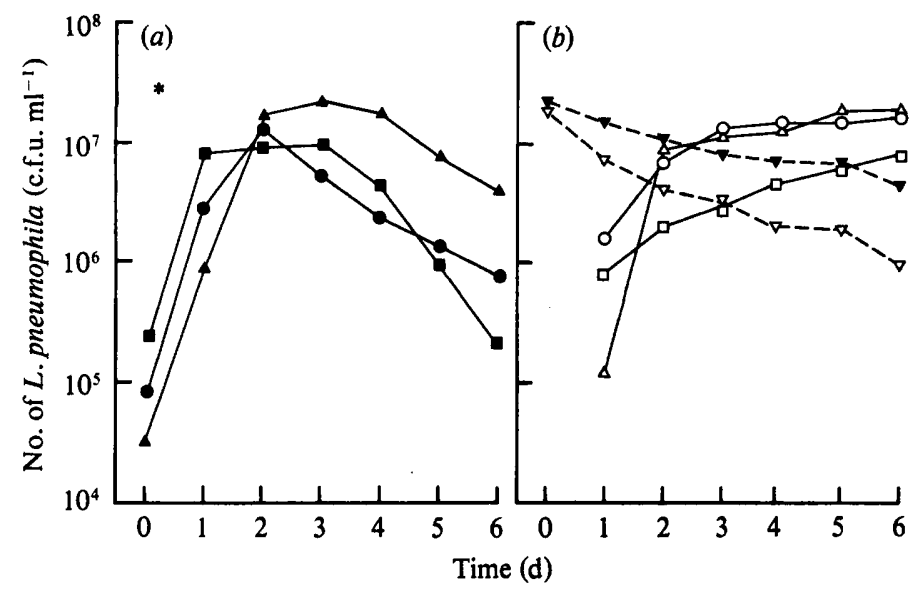

Fig. 1. Growth of L. pneumophila in cells in vitro. (a) Intracellular multiplication in MRC-5(O), HEp-2 $(\square)$ and Vero ( $\triangle$ ) cells. (b) Release of organisms from infected MRC-5 (O), HEp-2 ( $\square$ ) and Vero $(\triangle)$ cells into the extracellular fluids. Response of $L$. pneumophila to incubation in cell-free MEM $(\nabla)$ and $199(\nabla)$ culture fluids; ${ }^{*}$, inoculum. Similar results were obtained in three independent experiments.

Release of organisms from each of the three cell types into the suspending menstruum occurred progressively over the $6 \mathrm{~d}$ study period, but was most pronounced with the MRC-5 and Vero cells. The gradual release of the bacteria from the infected HEp-2 cells reflected the slower development of the cytopathic effect and the more chronic-type infection which occurred in these cells (Fig. 1 b). L. pneumophila inoculated into either MEM or 199 culture medium in the absence of cells failed to replicate (Fig. 1b).

\section{Morphological studies: light microscopy}

Inoculation of cell cultures with $L$. pneumophila was followed by the development of a cytopathic effect in all three cell lines. Although granulation of cells and eventual lysis were common to all three cell types, differences were noted in the distribution and rate of cell destruction. The lung fibroblasts developed rapidly progressive cytolytic changes distributed throughout the entire cell monolayer within $24 \mathrm{~h}$ of inoculation, with cell destruction complete by $96 \mathrm{~h}$. In contrast, the transformed human cells showed occasional rounded cells $48 \mathrm{~h}$ after bacterial inoculation and either a spreading focal or generalized granular cytopathic effect of the monolayers by 96 to $120 \mathrm{~h}$. After $48 \mathrm{~h}$ of infection, the organisms had induced changes in the Vero cells. These appeared as clumps of granular cells surrounding circumscribed zones of cell lysis, the size of which increased with incubation time.

\section{Morphological studies: electron microscopy}

Within $1 \mathrm{~h}$ of inoculation, legionellae were observed in loose combination with the surfaces of each of the three cell types. Binding of the organisms followed this initial contact and adherence bridging between the membranes of the bacteria and the eukaryotic cells was evident (Fig. 2). Attachment of organisms was often seen associated with thickening of the eukaryotic cell membrane in apposition to the region of bacterial contact. By SEM, this process was invariably associated with areas of the cell membranes possessing numerous microvilli and occasional filopodia. The presence of these cellular projections, which were rarely seen either in control cultures or areas of inoculated cells lacking attached legionellae, was in direct response to the organisms. Indeed, the microvilli appeared to extend towards the attached bacteria (Fig. $3 a$ ), were often in direct contact with them (Fig. $3 b$ ) and apparently initiated the process of cellular uptake into phagocytic-like vacuoles (Fig. 3c). Similar observations were made in thin sections, with engulfment of organisms mediated by microvilli by a process of 'bacteriopexis' which resulted in intracellular organisms (Fig. $3 d-g$ ). 


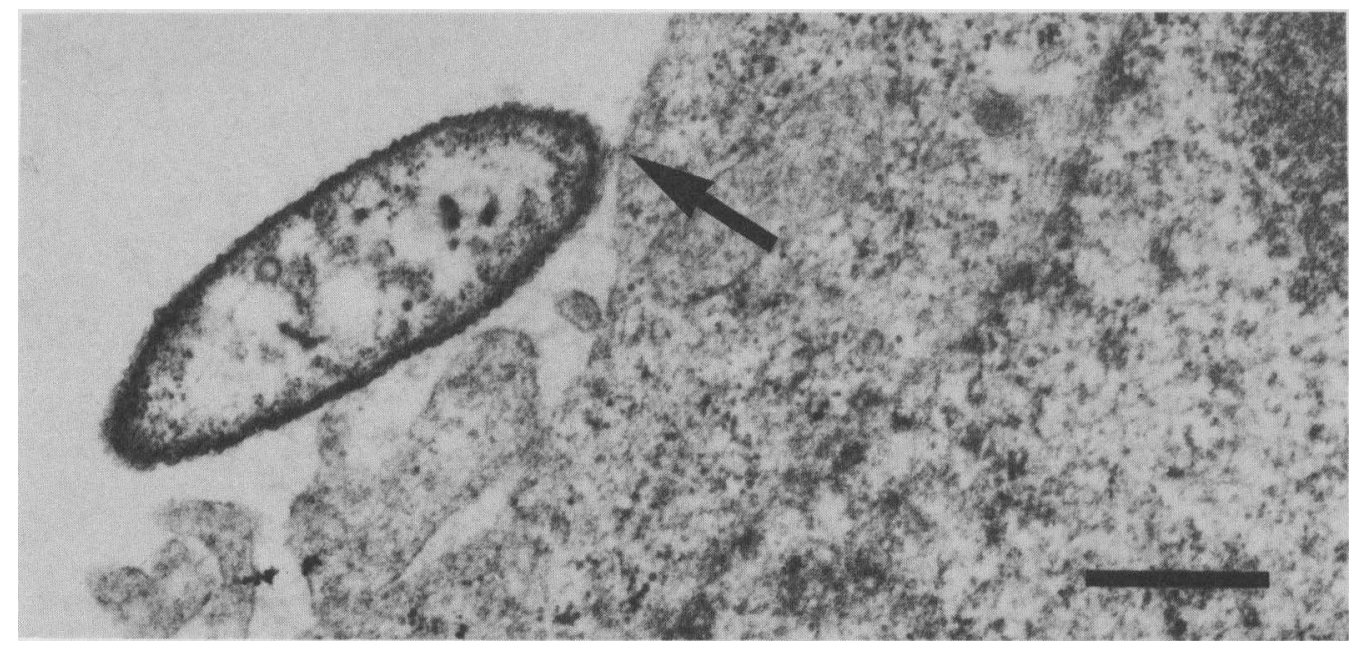

Fig. 2. TEM of the early phase of adhesion of $L$. pneumophila to the cell membrane of a HEp-2 cell in vitro. Note bridging point (arrow). Bar, $0.5 \mu \mathrm{m}$.

In the early stages of intracellular development, single organisms were observed in association with dense clusters of cytoplasmic filaments (Fig. $4 a$ ), often associated with vesiculation of the cytoplasm (Fig. 4b) and followed by dividing organisms within close fitting cytoplasmic vacuoles which were often lined with ribosomes (Fig. 4c). At this stage of uptake, organisms in vacuoles were frequently seen surrounded by cross-banded strands of cell cytoplasm (Fig. $4 d$ ). Thorium labelling demonstrated that organisms occurred within the cytoplasm of infected cells, and not in invaginations of the cytoplasmic membrane (Fig. 5a). The appearance of morphologically dividing organisms coincided with a decline in the number of organisms containing poly- $\beta$-hydroxybutyrate (PBH) granules together with an increased dilation of both the endoplasmic reticulum of infected cells (Fig. $5 b$ ) and the vacuoles containing organisms, often in the absence of ribosomes (Fig. 5c). The electron-lucent zones surrounding such intracellular organisms lacked acid polyanions as shown by ruthenium red labelling (Fig. $5 d$ ).

In the late stages of infection, distended vacuoles containing many organisms rich in PBH granules occupied most of the cell cytoplasm (Fig. $6 a$ ), and this, together with a paucity of cytoplasmic organelles in the infected cells, suggested end-stage replication of the bacteria with depletion of cell-derived nutrients. Although organisms were not found within the nuclei of infected cells, karyorrhexis and karyolysis were common as were fatty degeneration of the mitochondria and dilation of the perinuclear spaces and endoplasmic reticulum, suggestive of toxin-induced damage. Release of organisms into the extracellular fluids was by cell lysis (Fig. $6 b$ ). The sequence of development of legionellae in MRC-5 cells is outlined in Table 1.

\section{DISCUSSION}

L. pneumophila adhered to, penetrated and replicated within intracellular vacuoles in MRC-5, Vero and HEp-2 cells in vitro, inducing cytopathic changes. The outward spreading granular foci seen in the transformed cell lines by light microscopy, and the slow release of organisms, particularly from HEp-2 cells, were suggestive of a more chronic type of infection in these cells with some cell-to-cell spread of the bacterium. Electron microscopy confirmed the slow chronictype infection, in which all the stages of organism uptake and development were seen simultaneously throughout the study. In contrast, the rapidly lytic generalized infection of the MRC- 5 cells demonstrated their sensitivity to infection with the organism. The fastidious nature of this facultative intracellular pathogen was confirmed by its failure to replicate in the extracellular culture fluids per se. It does, however, replicate readily on selected artificial media (Edelstein, 1984) as well as in enriched broth (Rodgers et al., 1980). In supplying essential 

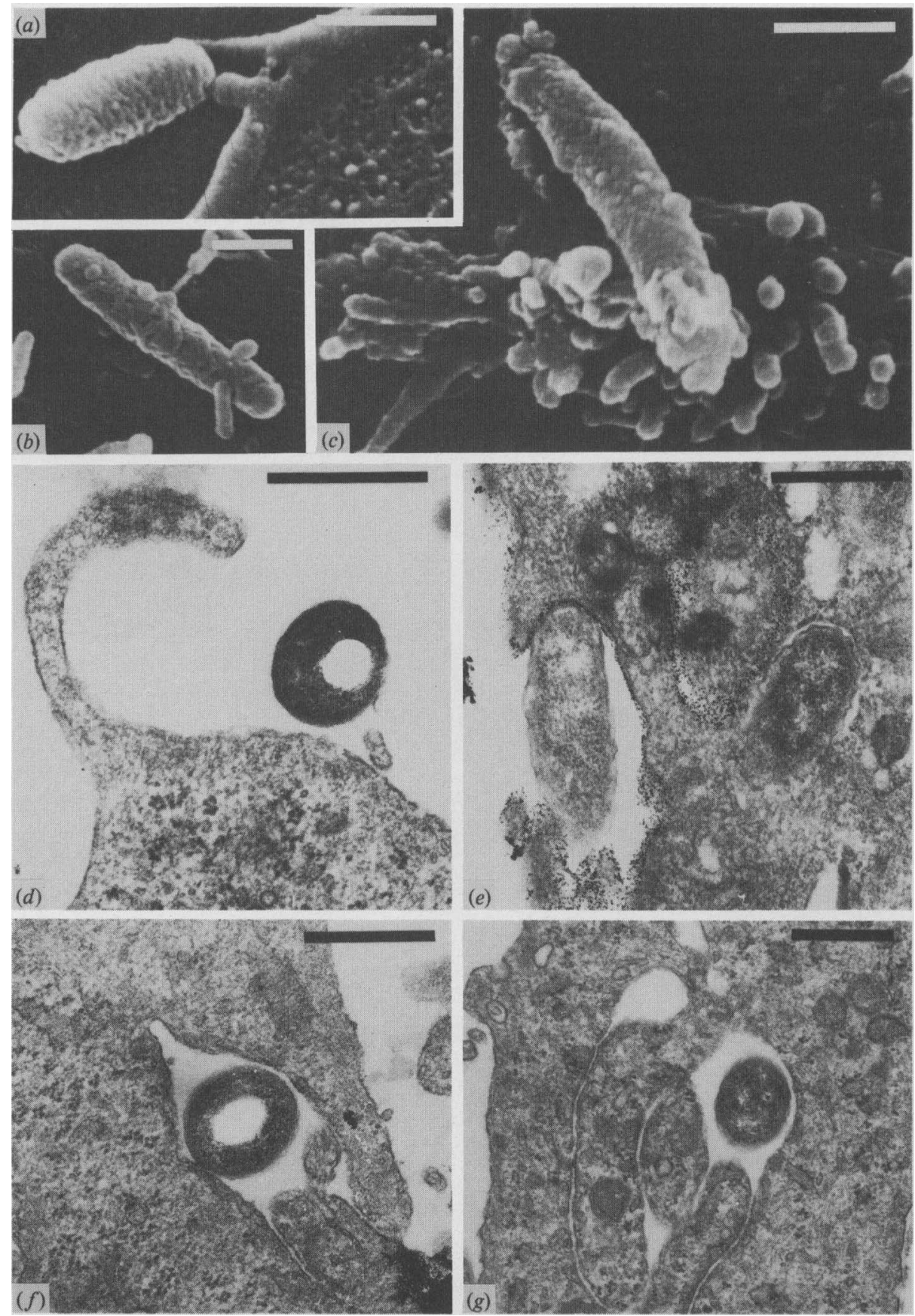

Fig. 3. Attachment and penetration of $L$. pneumophila in MRC-5 cells in vitro mediated by microvilli and filopodia. $(a, b)$ SEM of organisms attached to cell surfaces by microvilli at $2 \mathrm{~h}$ post-inoculation. Note microvilli appear to enfold bacteria. (c) SEM of similar organism at $4 \mathrm{~h}$ post-inoculation showing engulfment of one end of the bacterium by a mass of microvilli. $(d-g)$ TEM sequence showing stages of uptake by 'bacteriopexis'. Bars, $0.5 \mu \mathrm{m}$. 

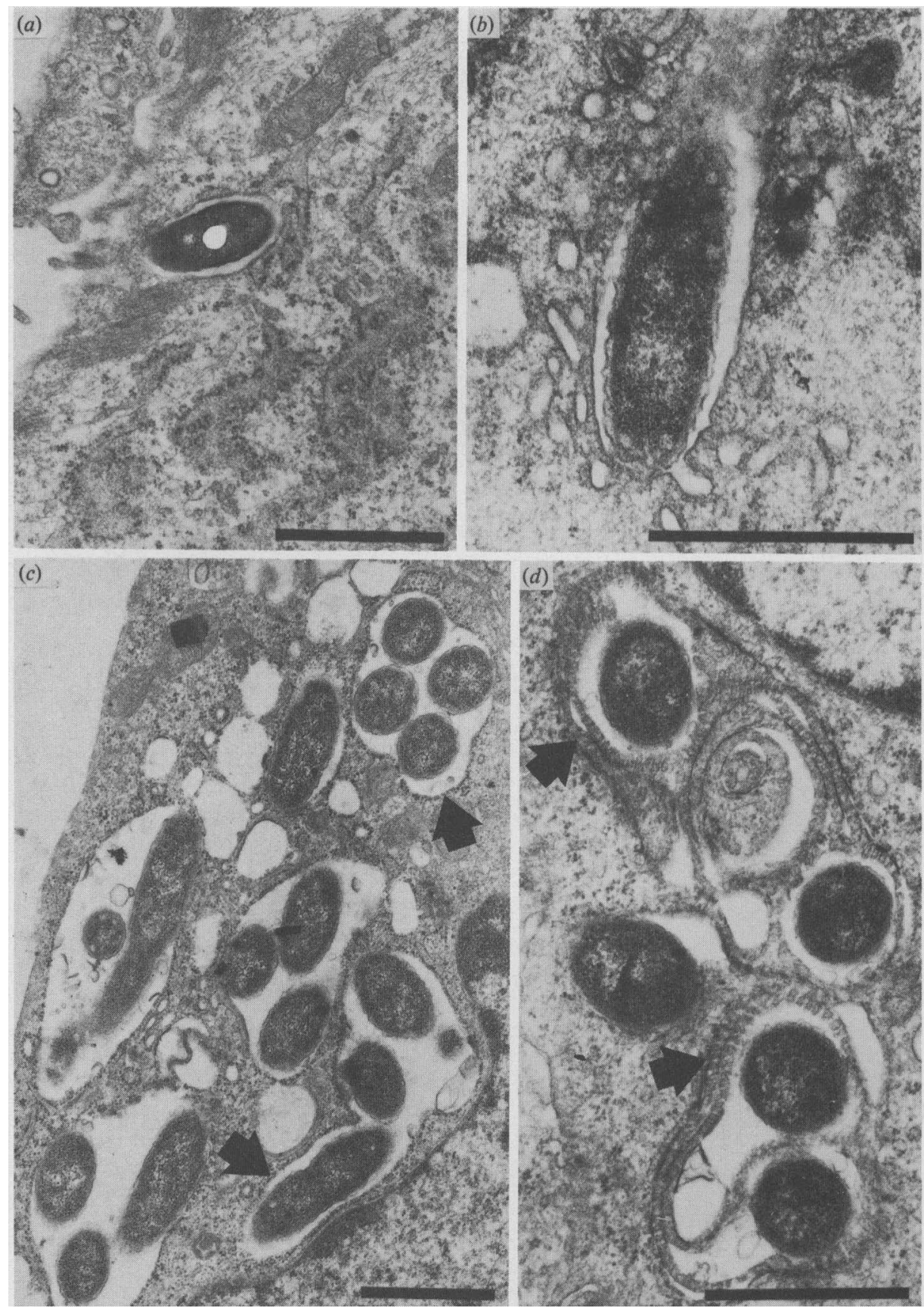

Fig. 4. TEM of the early stages of intracellular development of $L$. pneumophila. (a) Uptake associated with cytoplasmic filaments. (b) Organisms associated with vesiculation of the cytoplasm. (c) Replication within vacuoles lined with ribosomes (arrows). (d) Organisms enclosed within crossbanded cytoplasmic extensions (arrows) within vacuoles lined with ribosomes. $(a, b, d)$ MRC-5 cells; (c) HEp-2 cells. Bars, $1 \mu \mathrm{m}$. 

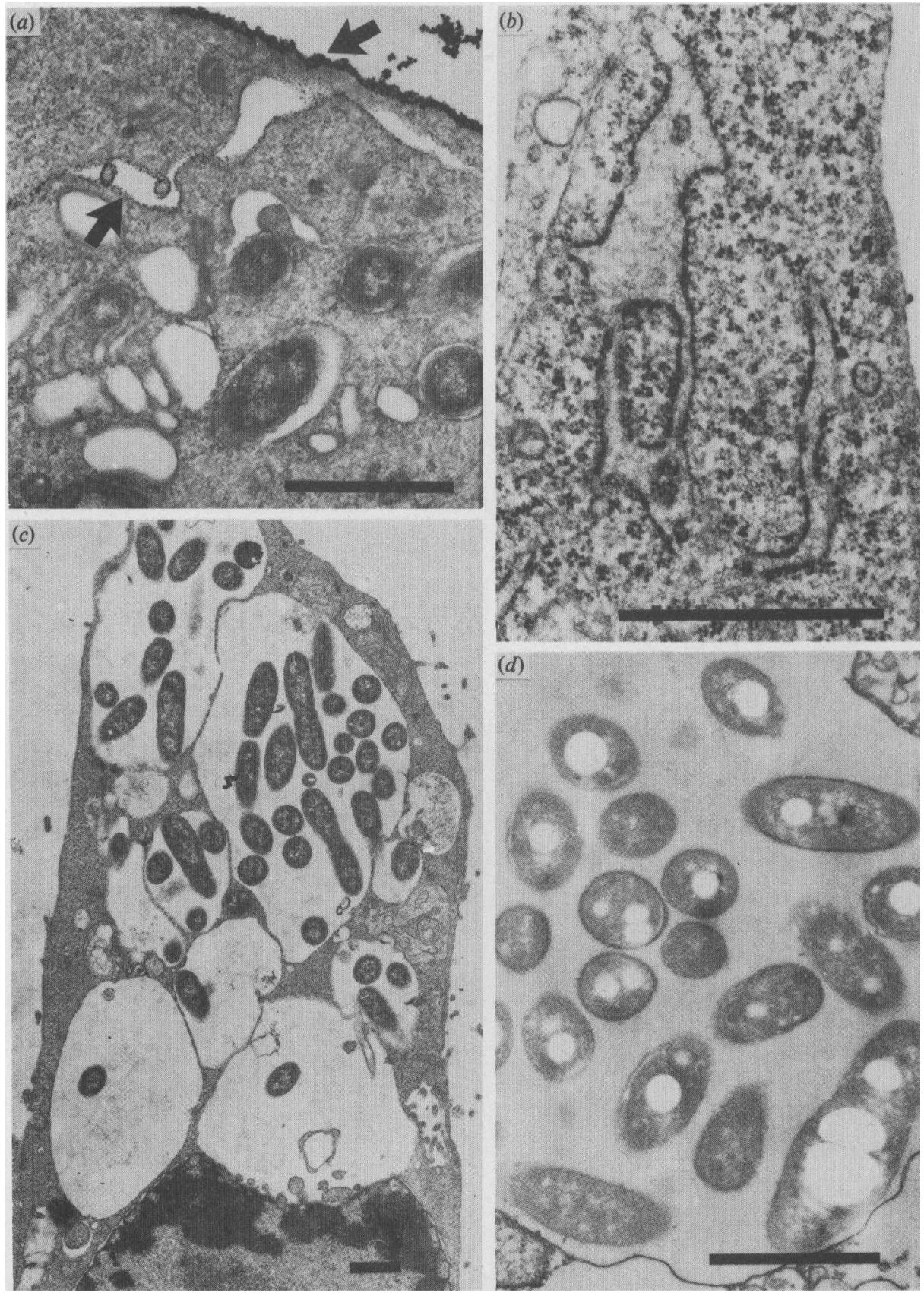

Fig. 5. (a) Thorium labelling of membranes (arrow) indicated that $L$. pneumophila multiplied within the cytoplasm of infected cells and not in invaginations of the cytoplasmic membrane. Note lack of electron-dense thorium label surrounding organisms in vacuoles. (b) Organism-induced dilation of the endoplasmic reticulum. $(c)$ Late stage infected cells with dilated vacuoles containing numerous dividing legionellae. $(d)$ Infected cell labelled with ruthenium red shows no acid mucopolysaccharide material surrounding the organisms either within vacuoles or in the process of release. $(a, b, d)$ MRC-5 cells; $(c)$ HEp-2 cells. Bars, $1 \mu \mathrm{m}$. 

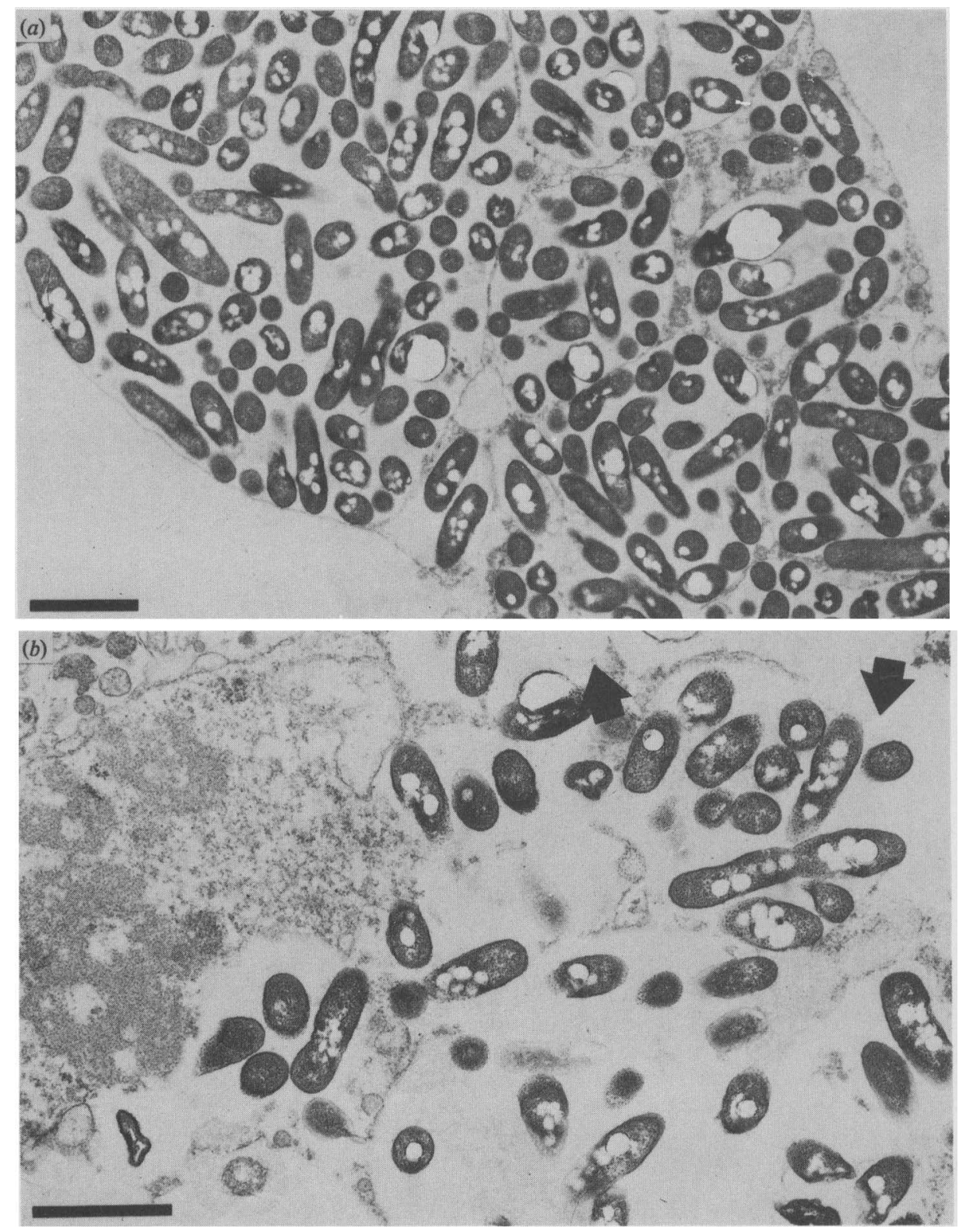

Fig. 6. Late stages of intracellular multiplication of $L$. pneumophila in MRC-5 cells. (a) Organisms occupy the entire cell cytoplasmic space at $3 \mathrm{~d}$ of infection. (b) Organisms released through breaks in the cell cytoplasmic membrane (arrow) effecting cell lysis, $4 \mathrm{~d}$ after inoculation. Note increase in number of bacteria possessing PBH granules. Bars, $2 \mu \mathrm{m}$.

nutrients, the cellular ribosomes and mitochondria located at the periphery of early infected vacuoles may be crucial to initiating intracellular multiplication. However, these structures were not found associated with vacuoles later in infection, despite continued bacterial multiplication. The precise role of eukaryotic organelles in the intracellular development of legionellae remains unclear. 
Table 1. Morphological features involved in the infection of MRC-5 cells by Legionella pneumophila

\section{Morphological feature}

Microvilli on cell surfaces associated with adherent organisms

Nature of vacuoles containing organisms:

tight, smooth

tight, ribosome-lined

distended, ribosome-lined

distended, smooth

Intracellular organisms closely associated with high

concentrations of :

cytoplasmic filaments

mitochondria

polyribosomes

vesiculation of cell cytoplasm

banded enclosures

Organisms:

rich in PBH granules

dividing intracellularly

releasing from cells

Toxic cellular changes

\begin{tabular}{|c|c|c|c|c|c|c|}
\hline \multicolumn{7}{|c|}{ Time post-inoculation $(h)^{*}$} \\
\hline 1,2 & 4,6 & 8 & 12,16 & 24 & 48 & $72,96,120$ \\
\hline+ & + & + & + & - & - & - \\
\hline+ & + & + & - & - & - & - \\
\hline - & - & \pm & + & - & - & - \\
\hline- & - & $\overline{-}$ & - & \pm & + & - \\
\hline- & - & - & - & - & + & + \\
\hline+ & + & + & \pm & - & - & - \\
\hline- & + & + & + & - & - & - \\
\hline+ & + & + & + & - & - & - \\
\hline- & - & \pm & + & + & + & - \\
\hline- & - & + & + & - & - & - \\
\hline+ & + & + & - & - & \pm & + \\
\hline- & - & - & + & + & + & + \\
\hline- & - & - & - & - & \pm & + \\
\hline- & - & - & - & - & \pm & + \\
\hline
\end{tabular}

* Feature commonly $(+)$, rarely $( \pm)$ and not $(-)$ observed.

Attachment of organisms to the cells was mediated by thickening of the eukaryotic cell membrane followed by the production of microvilli. That such structures occurred only in areas of bacterial attachment indicated that they appeared in direct response to organisms or organism-bound products rather than to soluble toxin. Bacterial uptake was completed by a process of 'bacteriopexis' following engulfment of organisms by microvilli in association with intracellular cytoplasmic filaments. The coiling phagosome described by Horwitz (1984) for human monocytes, primarily phagocytic cells, was not observed for the cells in this study. Both cross-banded cytoplasmic projections and the numerous vesicles enclosing organisms, which appeared during the active phase of bacterial multiplication rather than during uptake, probably reflected cellular responses to the production and release of toxins. It is also probable that it was the presence of toxins which eventually induced such cellular changes as dilation of the perinuclear spaces and endoplasmic reticulum, fatty degeneration of the mitochondria and breakdown of the nuclei. These toxin-induced changes together with physical distortion due to extensive intracytoplasmic bacterial replication led to the release of organisms by cell lysis. At this stage the reappearance of $\mathrm{PBH}$ granules within the legionellae indicated a depletion of intracellular nutrients.

The unresponsive nature of clinical legionellosis to treatment with many antibiotics is primarily due to the intracellular nature of the organisms in vivo and the inability of such antibiotics to permeate within cells. Further work is required to elucidate the virulence factors associated with $L$. pneumophila uptake and intracellular survival in eukaryotic cells. Current investigations involve characterization of the cellular and bacterial receptors involved in the attachment of legionellae and hence initiation of the infectious process. These cell culture studies serve as useful models of infection at the cellular level.

We thank Mrs N. Douglass for help in printing the electron micrographs and Mrs S. Brailsford for typing the manuscript. L. J.O. is a recipient of an MRC postgraduate training award. This study was presented in part at the 2nd International Symposium on Legionella, Atlanta, Georgia, USA, in June 1983. 


\section{REFERENCES}

Chandler, F. W., Cole, R. M., Hicklin, M. D., Blackmon, J. A. \& Callaway, C. S. (1979). Ultrastructure of the Legionnaires' disease bacterium. A study using transmission electron microscopy. $A n$ nals of Internal Medicine 90, 642-647.

DaisY, J. A., Benson, C. E., MCKitrick, J. \& FRIEDMAN, H. M. (1981). Intracellular replication of Legionella pneumophila. Journal of Infectious Diseases 143, 460-464.

Davis, G. S., Winn, W. C., Gump, D. W., Craighead, J. E. \& BeAty, H. N. (1982). Legionnaires' pneumonia after aerosol exposure in guinea-pigs and rats. American Review of Respiratory Disease 126, 10501057.

Dennis, P. J., Taylor, J. A. \& Barrow, G. I. (1981). Phosphate buffered, low sodium chloride blood agar medium for Legionella pneumophila. Lancet 2, 656 .

EDELSTEIN, P. H. (1984). Laboratory diagnosis of Legionnaires' disease. In Legionella, pp. 3-5. Edited by C. Thornsberry, A. Balows, J. C. Feeley \& W. Jakubowski. Washington: ASM.

Flesher, A. R., Ito, S., MANSheim, B. J. \& KASPER, D. L. (1979). The cell envelope of the Legionnaires' disease bacterium. Morphological and biochemical characteristics. Annals of Internal Medicine 90, 628630.

Friedman, R. L., Lochner, J. E., Bigley, R. H. \& IGLEWSKI, B. H. (1982). The effects of Legionella pneumophila toxin on oxidative processes and bacterial killing of human poly-morphonuclear leucocytes. Journal of Infectious Diseases 146, 328-334.

Glavin, F. L., Winn, W. C. \& Craighead, J. E. (1979). Ultrastructure of lung in Legionnaires' disease, observations on three biopsies done during the Vermont epidemic. Annals of Internal Medicine 90, 555-559.

HoRwITz, M. A. (1984). Interactions between Legionella pneumophila and human mononuclear phagocytes. In Legionella, pp. 159-166. Edited by C. Thornsberry, A. Balows, J. C. Feeley \& W. Jakubowski. Washington: A.S.M.

Horwitz, M. A. \& Silverstein, S. C. (1980). The Legionnaires' disease bacterium (Legionella pneumophila) multiplies intracellularly in human monocytes. Journal of Clinical Investigation 66, 441-450.
Horwitz, M. A. \& Silverstein, S. C. (1981). Interaction of the Legionnaires' disease bacterium (Legionella pneumophila) with human phagocytes 1 : L. pneumophila resists killing by polymorphonuclear leukocytes, antibody and complement. Journal of Experimental Medicine 153, 386-397.

Kishimoto, R. A., Kastello, M. D., White, J. D., Shirey, F. G., McGanN, V. G., Larson, E. W. \& Hedlund, K. W. (1979). In vitro interaction between normal cynolmolgus monkey alveolar macrophages and Legionnaires' disease bacteria. Infection and Immunity 25, 761-763.

Kishimoto, R. A., White, J. D., Shirey, F. G., MCGANN, V. G., BERENDT, R. F., LARSON, E. W. \& Hedlund, K. W. (1981). In vitro response of guineapig peritoneal macrophages to Legionella pneumophila. Infection and Immunity 31, 1209-1213.

RODGERS, F. G. (1979). Ultrastructure of Legionella pneumophila. Journal of Clinical Pathology 32, 11951202.

RoDgers, F. G. (1983). The role of structure and invasiveness on the pathogenicity of Legionella. Zentralblatt für Bakteriologie, Mikrobiologie und Hygiene (Abteilung I, Originale A) 255, 138-144.

RODGERS, F. G. \& DAVEY, M. R. (1982). Ultrastructure of the cell envelope layers and surface details of Legionella pneumophila. Journal of General Microbiology 128, 1547-1557.

Rodgers, F. G., MaCrae, A. D. \& Lewis, M. J. (1978). Electron microscopy of the organism of Legionnaires' disease. Nature, London 272, 825-826.

Rodgers, F. G., Greaves, P. W., Macrae, A. D. \& LEWIS, M. J. (1980). Electron microscopic evidence of flagella and pili on Legionella pneumophila. Journal of Clinical Pathology 33, 1184-1188.

Winn, W. C., Davis, G. S., Gump, D. W., Craighead, J. E. \& BEATY, H. N. (1982). Legionnaires' pneumonia after intratracheal inoculation of guinea-pigs and rats. Laboratory Investigation 47, 568-578.

Wong, M. C., Ewing, E. P., Callaway, C. S. \& PEACOCK, W. L. (1980). Intracellular multiplication of Legionella pneumophila in cultured human embryonic lung fibroblasts. Infection and Immunity 28 , 1014-1018. 